\title{
The Distinction and Controversy of Digital Currency in China
}

\author{
G. Zhu, X. J. Wei \\ School of Information Management \\ Beijing Information Science and Technology University \\ 100192, Beijing, P. R. China
}

\begin{abstract}
This paper pointed out the main difference between digital currency and the other two currencies, by clarifying and comparing the concepts of electronic money, virtual currency and digital currency. Starting from the basic characteristics of digital currency, two controversial issues were reviewed and discussed, i.e. whether digital currency is trustworthy and will it become a real currency. Analysis indicates that the prospect of digital currency as a disruptive innovation should not be underestimated, but its healthy development cannot be guaranteed without recognition of the government and protection of laws, as well as compromising and integrating innovation with traditional financial system. Finally, the paper pointed out the current research directions of digital currency.
\end{abstract} BitCoin

Keywords-digital currency; electronic money; virtual currency;

\section{INTRODUCTION}

Marx's political economics believes that the currency is fixed as general equivalent goods. The measure of value and means of circulation is the basic function of money. But the means of payment and storage and the currency of the world are thought to be derived from the two basic functions of the monetary function.

Currency is classified according to the is suers. In addition to the fiat currency authorized to be is sued by the government, private currency may also be issued by non-government organizations. According to the physical form of the currency, it can be divided into real currency and virtual currency. For example, QQ Coins issued by Tencent should belong to private currency and virtual currency.

With the development of information technology and the wide application of the Internet, a new form of currency to exercise all or part of the functions of currency began to appear. Unlike the traditional material form of currency, it is Internet-based and virtualized currency, in the forms of credit card, game coins, accu mulate points, electron ic wallet, bit coin, etc. And they were given different names, such as network currency, electronic currency, virtual currency and digital currency. This article first defined the concepts and the existing forms of currency, and then compared and analyzed the digital currency, especially, BitCoin. And we also organized the different points of view of BitCoin, discuss the future development and administration of BitCoin.

For a long time, academic researchers often mixed using the concepts of electronic money, virtual currency, and digital money and so on. Here, we offer a clear distinction and comparison. In the following sections, this paper will attempt to define the above concepts from both the broad and the narrow sense.

\section{FROM ELECT RONIC AND VIRT UAL CURRENCY TO DIGIT AL CURRENCY}

Electronic money is a kind of electronic legal tender, usually stored in the magnetic card or account in the financial information system, to facilitate the storage and payment. The value of the digital currency equals that of the legal currency. Based on different distributors, it can be divided into bank card, and stored value card.

The bank cards are debit cards, credit cards, etc. which are issued by the bank. It is the extension of banking information business, such as credit card payment, telephone banking. The stored value card is another kind of electronic money which is issued in an area or areas by the enterprise or institution used for payment. In essence, it is more like our electronic wallet whose main function is like a bill of lading, convenient for payment, especially for the small payment. Due to the need for credit and payment in e-commerce transactions, Internet companies developed the third party pay ment account, such as Paypal, Alipay, Tenpay etc.

In short, electronic money is the electronized and networked legal tender in the bank or other financial institutions in when stored and used in payment. Trust in the electronic money come from the confidence of government fiat money and the normal operation of the banking and financial system.

Compared to the legal currency used in daily life, currency without the physical form can be referred to as "virtual currency" in a broad sense, even including the above mentioned electronic currency and digital currency which will be introduced next. But virtual currency in the narrow sense is based on the virtual network. It is issued by the network operator and used in virtual network space. It is just like the legal tender, that is, it is a mapping simulation of real world monetary system, also known as network currency. For example, Tencent issued QQ coins, online games companies issued the currency of the game, and the forum designed the accumulate points to award Internet users' participation and contribution, etc., which are often referred to as virtual currency in a narrow sense.

The use of virtual currency is often defined in the business realm, the purpose of which is to facilitate Internet users' measurement, exchanging, and enjoy the Internet services. 
Because Internet services facing the netizens feature "small amount" and "frequent transactions", in the absence of mature credit system and method of payment, Internet companies issuing currency can achieve the network payment of "one purchase, used many times", therefore currency can be seen as a data of bills of lading. Trust in virtual currency completely comes from their confidence on the is suing Internet companies.

Digital currency can be considered as a virtual currency which is based on individual nodes of the network and digital encryption algorithm.

The emergence of BitCo in presents a great challenge to the existing monetary system. Although it belongs to the generalized virtual currency, BitCoins has the essence of distinguishing from the virtual currency which is issued by Internet companies, so we call it a digital currency.

The core features of digital currency are mainly embodied in three aspects: 1) Because it comes from some open algorithm, digital currency does not have a issuer, so no person or institution can control its release; 2) As the number of algorithm is determined, so the total number of digital currency is fixed. For example, the total number of BitCoins is $21,000,000$, and the total number of litecoin is $84,000,000$, which fundamentally eliminates the virtual currency spam which may lead to inflation; 3) Because the transaction process needs the approval of every node in the network, it is safe enough in the transaction process of digital currency.

BitCoin is the first digital currency. Hundreds of digital currency appeared in the Internet in a similar form. In the following sections, we will analy ze and compare two kinds of most representative digital currencies (see Table 1)

TABLE I. THE COMPARISON OF BITCON AND LITECOIN.

\begin{tabular}{|c|c|c|}
\hline & BitCoin & Litecoin \\
\hline Introducer & Satashi Nakamoto & Charles Lee \\
\hline Date issued & 2008.11 .1 & 2011.10 .7 \\
\hline Algorithm & SHA-256 & Scrypt \\
\hline The processing time & 10 minutes & 2.5 minutes \\
\hline Anticipated number & 21 Million & 84 Million \\
\hline Split unit & 0.00000001 & 0.00000001 \\
\hline
\end{tabular}

\section{THE CONTROVERSY OF DIGIT AL CURRENCIES IN CHINA}

$\mathrm{Wu}$, Fang and Zhang (2013) think that digital currency is the ideal lifestyle for the extreme libertarians, because it not only does not solve the network's payment security, but also brings in the hidden dangers, which could used by illegal traders, so it is not worth trusting, not to mention investment [1]. Zhang and Xue (2013) think that BitCoin is similar with the gold standard. By analyzing the defects of BitCoin itself and the reason of the collapse of the gold standard, they point out that BitCoin is the wishful thinking of those who support the restoration of the gold standard [2]. Wang (2014) analysed that the digital currency does not have the nature of money from the angle of the essence of currency, but it is evolving into a speculative tool recently, so it is very necessary to limit it [3]. Liao (2014) think BitCo in market price now is far away from its intrinsic value, so there is a huge bubble. Therefore, investing or speculating in BitCoin is the worst choice [4]. Some people think digital currency is the modern version of the Holland tulip, or even a Ponzi scheme.

The paper does admit that the huge increase in digital currency price is in large related to the shortage of investment market. However, we need to think about why the digital currency led by BitCoin is crazy speculation. This paper argues that this is a necessary process in the digital currency's initial capitalization. In this process, risk caused by constantly buying and selling and the price fluctuation led to the market speculation and and it cannot directly create social wealth. And the huge floating in price is not helpful for digital currency as the currency of payment and measure of value, but you cannot deny that it is a powerful signal of the capital market, and it represents the confidence of capital on the future of digital currency.

Review of the development of the Internet economy, in 1995, based on the electronic commerce network began rising in the world, after just a few years' development and cognition in 1999 the global capital crazy influx into the Internet industry, resulting in the subsequent Internet bubble. However, the bubble has clearly shows that the capital market's confidence in the Internet industry, At that time, the things what were seemingly have been excessive invest of Internet infrastructure, such as build the backbone network repeat and the surge in broadband, now it seems that it is laid the foundation for the past more than ten years of rapid development of the network economy. Therefore, the huge increase in current digital currency at least display that the global capital market are confident in the currency in the future. Just as the internet cannot subvert the traditional economy, it is just like a comprehensive optimization and upgrading of traditional mode of economic operation. This paper argues that digital currency can not completely replace the existing money, but it can promote the traditional financial system's reform, innovation and integration, optimize and upgrade the existing network payment and virtual economy.

Wang (2003) points out that monetary and financial has the virtual naturally, and with the spread of economic globalization and financial derivative products, the virtualization of the traditional financial system has begun to gradually weaken the monetary and financial systems at home and abroad [5]. The Nobel laureate Freedman through the empirical analysis in the book Monetary history of USA shows that the Great Depression in 1930s and the monetary aggregates and deliberate control are not unrelated, however the 2008 Asian financial crisis, even the government of Zimbabwe issued the world's largest amount of banknotes phenomenon can explain that nearly a hundred years of national credit legal tender system indeed has inherent defects, its credit is not put things right once and for all and be too strong to break. The emergence of digital currency at least provides beneficial reference for the reform of the international monetary and financial system.

With the popularization and application of innovative of digital currency, the credit increases gradually upgrade with the global use of the number, scope and influence. As for the digital value of the currency, no one can accurately predict 
whether it is overvalued or have a greater appreciation of space in the short term. But considering that the value is guided by the demand, this paper believes that after a competitive game (even non equivalence) and international governance, the multinational Fiat and a variety of digital currency will then tends to a relatively stable and steady upward state. It will complete, supervise and balance the traditional financial system which is based on the national credit.

If only consider the basic function of money, digital currency can achieve all the basic functions of money, especially as the function of storage and the currency of the world.

However, viewing from the actual situation, there are different views from many scholars about whether digital currency has the real monetary attributes. For example, Wang and Zhou (2014) believe that BitCoin is extremely close to the nature of the currency and its other functions, but as its inherent features in the issuing mechanism (total fixed, produce speed determined by the algorithm), it is difficult to replace paper money to become the future currency [6]. Jia (2013) thinks that BitCoins basically has the function and some attributes of money, but it do not necessarily real money. If it can transit to the real currency depends on the trust of people to BitCoin, and the confidence to its mechanisms [7]. Yang (2014) thinks that digital currency has no money property, the main reason is that it is not issued by the monetary authorities, does not have legal tender and mandatory, and it absence the necessary credit basis of money, cannot reflect the specific social relations of production, and lack the security of monetary assets [8].

Electronic currency is the extension of legal currency, it has legal and mandatory, but digital currency within a short period of time may not be acknowledged and accepted by the governments and to be a true currency it may still have a long way. According to the survey of Forbes in early 2014, only a few countries such as Germany and the United States release some kind of goodwill to BitCo in transaction, and intend to put it into the category of financial supervision. Most countries take the cautious of wait-and-see attitude, not support. Otherwise a few countries such as China and Brazil on dig ital currency trading take imposed attitude. So far, although many countries take the virtual goods as digital currency and it can be freely traded, but no any government admit its legality.

Although some institutions or merchants accept digital currency in the market, digital currency as a means of payment is still relatively uncommon. Many scholars think that this is the phenomenon that "bad money drives out good" under the "Gresham's law ". Due to the fixed total of circulation digital currency, it is bound to cause deflation. No one took out good money which will be rise as a means of payment.

Here suggests that digital currency to become real currency is facing two major problems in reality: Firstly, governments' attitude to digital currency and the corresponding laws and regulations are important factors affecting the future development of digital currency. To select the open, innovation and regulation or to select conservative, restricted and prohibited will directly influence the adoption and popularize of digital currency in different countries. Secondly, even in a relaxed environment, due to the technical threshold of safety and convenience of digital currency transactions, it is still relatively high for ordinary people, so the universally adoption of digital currency in the market still need the technological innovation, innovation of application and relevant laws and regulations to follow up.

\section{SUMMARY}

Unlike the surplus value theory of Marx economics, information economist Knight argues that the profit of capitalists comes from the uncertainty and venture of the market. Profit is the return of risk in capital investment. However, the theory of innovation from Schumpeter further emphasizes that continuous innovation is the source of social wealth increment. The author thinks that technology and innovation are the unstoppable force of social progress, and the emergence of digital currency will certainly influence and optimize the traditional financial system. Therefore, the craze of global capital to digital currency reflects its approval of the market to some extent. However, at present digital currency which appears as a subversive purpose dose not achieve the government's understanding and support. Therefore, its future development has great controversy and uncertainty. Through literature review and investigation, this paper argues that the future development of digital currency cannot do without the approval of government, the protection of law and the cooperation of financial system. The process of entry which disturbs the game may be a long process. In the future digital currency's innovation and application needs compromise, cooperation and integration with the traditional financial system, but this process is not a completely opposite the game.

In this paper, there are four directions of the future research as the following: 1) The influence of other governments' policy on digital currency on China's financial system. And how to occupy a favorable position in the new round and changeable global financial system.2) How the Internet enterprises to continue innovation and application of digital currency in the field of payment network and Internet in the finance, and cooperate with the traditional financial system. 3) The existing financial system how to participate in and even lead the development of the digital currency, actively carry out integration and innovation. 4) How to research the digital currency regulation and control measures from the point of view of user, business, industry, and government, and to protect the balance of multiple interests.

\section{ACKNOWLEDGEMENT}

The paper is sponsored by China National Nature Science Fund (No: 612722513).

\section{REFERENCES}

[1] H. Wu, Y. Q. Fang \& Y. Zhang, A Crazy Digital Currency--Nature of Bitcoin and its enlightenment. Journal of Beijing University of Posts and Telecommunications (Social Sciences Edition), 15(3):3, 2013.

[2] G. W. Zhang \& J. J. Xue, Bitcoin: the restoration of the gold standard type of wishful thinking. Modern Economic Information, 10: 242, 2013.

[3] Wang N. From the standpoint of monetary essence, the attribute of the currency. Commercial Times, 19: 038, 2014. 
[4] Y. P. Liao, Analysis and reflection on development stage of BitCoin financial market. Joumal of Chongqing Technology and Business University (West Fonum), (3):73-80, 2014.

[5] Z. G. Wang, Economic Globalization and financial virtual. Finance Forum, 8(8): 2-7, 2003.

[6] Y. Wang \& G. Y. Zhou, The Analysis of the Monetary Attribute of Bitcoin. Journal Of Jiangxi Finance College, 27(3): 3-7, 2014.

[7] L. P. Jia, BitCoin theory, practice and impact. Studies of International Finance, (12): 14-25, 2013.

[8] T. Yang, Non-monetary property of BitCoin. Times Finance, (1): 93-96, 2014. 